\title{
Fibrinogen and D Dimer in Healthy Nigerian Women on Hormonal Contraceptives
}

\author{
Sani Bako Abubakar ${ }^{1 *}$, Aisha Indo Mamman², Muhammad Adogie Abdul ${ }^{3}$ and Muhammad ZainuSabitu ${ }^{4}$ \\ ${ }^{1}$ Department of Haematology and Blood Transfusion UsmanuDanfodiyo University Teaching Hospital Sokoto, Nigeria \\ ${ }^{2}$ Department of Haematology and Blood Transfusion Ahmadu Bello University Teaching Hospital Zaria, Nigeria \\ ${ }^{3}$ Department of Obstetrics and Gynaecology Ahmadu Bello University Teaching Hospital Zaria, Nigeria \\ ${ }^{4}$ Department of Medical Microbiology UsmanuDanfodiyo University Teaching Hospital Sokoto, Nigeria
}

\begin{abstract}
Introduction: Hormonal contraceptives have been associated with increased tendency of thromboembolic disorders. However, a balance between fibrin generation and fibrinolytic activity has been shown to minimize the risk. The aim of the study was to assess the serum fibrinogen and D-Dimer level in hormonal contraceptives users.

Methods: A total of 160 consenting participants made of 80 subjects on different forms of hormonal contraceptives and 80 controls on non hormonalIUCD were recruited into this study. A structured questionnaire was administered to obtain information required; blood samples were collected from each of the participant into appropriate containers using standard methods. Fibrinogen assay was done using the STAGO STart®4 coagulation analyzer while D-dimer was measured using ZYMUTEST DDIMER ELISA kit (HYPHEN BioMed). The results were analyzed using SPSS version 17.0 software. Statistical significance was based on p value $<0.05$.

Results: The mean fibrinogen levels of the study group and controls were $387.10 \pm 62.52$ and $276.85 \pm 52.70$ respectively, (reference range $180-400 \mathrm{ng} / \mathrm{ml}$ ). The mean D dimer concentrations of the study group was markedly elevated $813.36 \pm 212.35$ while that of the controls was $257.04 \pm 108.33$ (reference range $<400$ ). Both analytes showed a statistically significant difference between the study group and control $(\mathrm{P}<0.05)$. None of the client on COCP has elevated D dimer level.

Conclusion: The significant increase in the procoagulant protein- fibrinogen and corresponding increase in fibrinolytic activity as demonstrated by elevated Ddimer level reflect a balance between fibrin formation and degradation hence minimizing the VTE risk. This balance is less prominent with use of COCP and can be attributed to the oestrogen component.
\end{abstract}

Keywords: D Dimer, Fibrinogen, Hormonal Contraceptive

\section{Introduction}

Hormonal contraceptives are birth control methods that act on the endocrine system. They are basically composed of the steroid hormones; oestrogen and progestogens. These drugs act by decreasing the pulsatile release of gonadotrophin releasing hormone and follicle stimulating hormone from the hypothalamus and pituitary respectively. This suppresses ovarian activity with resultant failure of follicular maturation and absence of ovulation. They also induce endometrial changes that make it unreceptive to the blastocyst in addition to alteration of tubal epithelium and increasing the viscosity of cervical mucus; thus adversely affecting the gamete motility and transport. ${ }^{[1]}$

Available hormonal contraceptives including oral contraceptives, injectables and implants are widely used all over the world with over 100 million users. ${ }^{[2]}$ Though they have important health benefit they also pose significant health risk to the user.

Documented side-effects of hormonal contraceptives such as fluid retention, altered menstrual cycle, breast engorgement and hirsutism are mild and transient, ${ }^{[3]}$ others are increased predisposition to hypertension, vascular disorders like myocardial infarction and venous thromboembolism. ${ }^{4}$

Hormonal contraceptive related thromboembolism results from increased procoagulant protein activity and inhibition of fibrinolysis. Added risk factors for thromboembolism are stasis, increased platelet activation, and decreased naturally occurring anticoagulant activity. ${ }^{[5,6]}$

\section{Materials and Method}

This was a cross sectional study carried out at the Reproductive health clinic, Department of Obstetrics and Gynecology and the Department of Haematology Ahmadu Bello University Teaching Hospital (ABUTH) Zaria, Nigeria.

The ABUTH Reproductive health clinic has an average of 355 clients monthly. About 1,380 clients are on hormonal contraceptives.

Ethical clearance was obtained from the hospital health research ethical committee. Consecutive subjects who were 
on hormonal contraceptives for at least six months with absence of intercurrent medical illness and no previous history suggestive of haemostatic disorders were enrolled into the study as they presented to the clinic for routine follow up (convenient sampling method) after obtaining there informed consent.

Using standard statistical methods, based on the prevalence of contraceptive use in Nigeria(5\%); a total of 80 subjects (study group) on different forms of hormonal contraceptives (Oral, injectables, intradermal implant, and hormone containing IUD) and 80 controls on non hormonal IUCD were recruited into this study. A structured questionnaire was administered to obtain relevant demographic data and other information required.

Four and half (4.5mls) of blood was collected from each participant into a test bottle containing $0.5 \mathrm{mls}$ of $3.2 \%$ Sodium citrate. The citrated sample was centrifuged at $1500 \mathrm{~g}$ for $15 \mathrm{mins}$ and the platelet poor plasma separated for assay of plasma fibrinogen within 2 hours of collection using the STAGO STart ${ }^{8} 4$ coagulation analyzer. Also the plasma were stored in aliquots in plastic tubes frozen at a temperature of $-30^{\circ} \mathrm{C}$ until the required number was obtained; and thawed just prior to use for D-dimer assay using ZYMUTEST DDIMER (COMPLETE ELISA kit for the assay of human DDimer) HYPHEN BioMed. The results were analyzed using the statistical package for social sciences (SPSS) version 17.0 software. Statistical significance was based on $\mathrm{p}$ value $<0.05$. Clients with abnormal results were contacted, informed and referred to appropriate clinics.

\section{Results}

The Majority of the participants were married. Only $4.3 \%$ of the study group and $10.0 \%$ of the controls were not married. Most of the participants had formal education and are civil servants and businesswomen (Table 1).

Age Distribution: The Majority of the participants were between the age of 26 and 40 years The mean age of the study group was $32.98 \pm 5.95$ while the mean age of the control was $32.37 \pm 5.47$. There is no significant difference between the ages of the study group and controls $(p>0.05)$ (Figure1)..

Type of Contraceptive being used by Participants: All the controls $(100 \%)$ were on non-hormone containing IUCD. While the subjects were on various forms of hormonal contraceptives, COCP being the most commonly used $(36.4 \%)$ as shown in figure 2.

Haemostatic Tests: The mean Fibrinogen concentration and $\mathrm{D}$ dimer level of the study group were found to be much higher compared with that of the controls and showed statistically significant differences; $\mathrm{P}<0.05$ (Table 2).

Comparison of Tests among users Based on Type of Hormonal Contraceptive: Large percentage of the client on COCP (62.7\%) has increased plasma fibrinogen level while none of them has elevated D-dimer, which reflect increase fibrinogen production with minimal fibrinolytic activity. This is in contrast to what was observed in users of other forms of contraceptive as shown in Table 3.

Table 1: Socio-demographic characteristics of the participants.

\begin{tabular}{|l|c|c|}
\hline Characteristics & $\begin{array}{c}\text { Study Group } \\
\mathbf{n = 8 0}\end{array}$ & $\begin{array}{c}\text { Controls } \\
\mathbf{n}=80\end{array}$ \\
\hline \multicolumn{2}{|c|}{ Marital status } \\
\hline Married & $(95.7 \%)$ & $(90.0 \%)$ \\
Single & $(4.3 \%)$ & $(10.0 \%)$ \\
Level of education & $(26.4 \%)$ & $(53.3 \%)$ \\
Tertiary & $(38.6 \%)$ & $(35.0 \%)$ \\
Secondary & $(21.4 \%)$ & $(5.0 \%)$ \\
Primary & $(13.6 \%)$ & $(6.7 \%)$ \\
No formal education & & $(23.3 \%)$ \\
Occupation & & $(28.4 \%)$ \\
Business & $(30.7 \%)$ & $(33.3 \%)$ \\
Civil servant & $(32.9 \%)$ & $(15.0 \%)$ \\
Student & $(25.0 \%)$ & \\
Full time Housewives & $(11.4 \%)$ & \\
\hline
\end{tabular}


Table 2: Result of tests among the study group and control.

\begin{tabular}{|l|l|l|l|}
\hline Test & Participants & Mean \pm SD & P value \\
\hline $\begin{array}{l}\text { Mean Fibrinogen } \\
\text { (mg/dl) }\end{array}$ & $\begin{array}{l}\text { Study group } \\
\text { Control }\end{array}$ & $387.10 \pm 62.52$ & $<0.05$ \\
\hline $\begin{array}{l}\text { Mean D -dimer } \\
\text { (ng/ml) }\end{array}$ & $\begin{array}{l}\text { Study group } \\
\text { Control }\end{array}$ & $816.85 \pm 52.70$ & $<0.05$ \\
\hline
\end{tabular}

Reference values: Fibrinogen 180-400 mg/dl, D-dimer $<400 \mathrm{ng} / \mathrm{ml}$

Table 3: comparison of fibrinogen and D dimer level between users of different forms of hormonal contraceptives.

\begin{tabular}{|l|l|l|l|l|l|l|l|}
\hline Test & $\begin{array}{l}\text { Observed } \\
\text { Results }\end{array}$ & $\begin{array}{l}\text { COCP } \\
\mathbf{N}=\mathbf{2 7}\end{array}$ & $\begin{array}{l}\text { POP } \\
\mathbf{N}=3\end{array}$ & $\begin{array}{l}\text { NOR } \\
\mathbf{N}=\mathbf{2 1}\end{array}$ & $\begin{array}{l}\text { DEPO } \\
\mathbf{N}=10\end{array}$ & $\begin{array}{l}\text { IMPLANT } \\
\text { N=15 }\end{array}$ & $\begin{array}{l}\text { HORM IUD } \\
\text { N=4 }\end{array}$ \\
\hline Fibrinogen & Normal & $37.3 \%$ & $66.7 \%$ & $66.7 \%$ & $38.9 \%$ & $44.4 \%$ & $50.0 \%$ \\
\hline D-dimer & Increased & $62.7 \%$ & $33.3 \%$ & $33.3 \%$ & $61.1 \%$ & $53.6 \%$ & $50.0 \%$ \\
\hline & Normal & $100 \%$ & $33.3 \%$ & $39.4 \%$ & $16.7 \%$ & $37.0 \%$ & $25.0 \%$ \\
\hline
\end{tabular}

Reference values: Fibrinogen 180-400 mg/dl, D-dimer $<400 \mathrm{ng} / \mathrm{ml}$

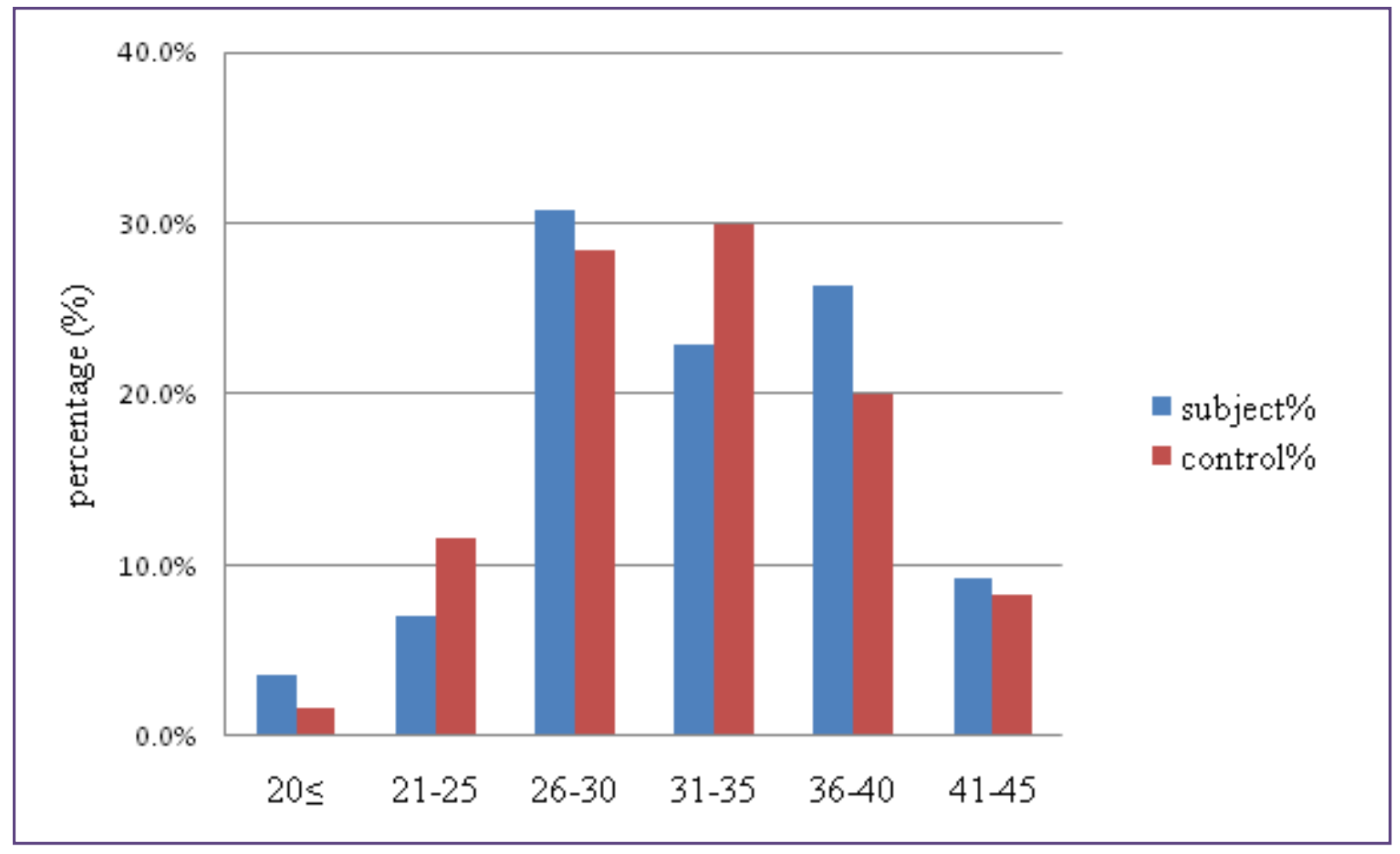

Fig. 1: Age distribution of participant. 


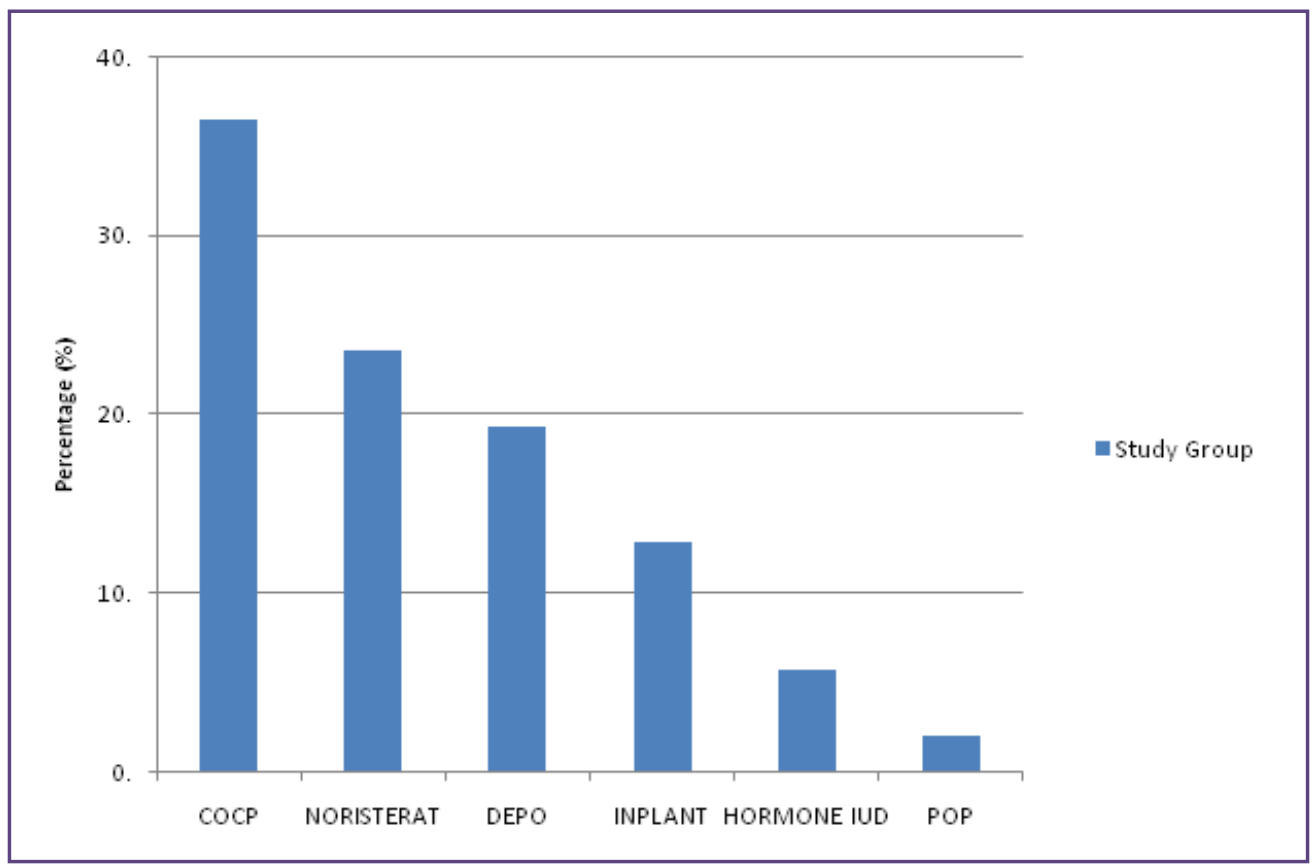

Fig. 2: Type of contraceptive used by participants.

\section{Discussion}

The majority of the participants in this study ( $81 \%)$ had at least high school education, Also, over two thirds of the participants $(69.0 \%)$ are either civil servants or are engaged in some form of trading. These findings are in agreement with the National Demographic and Health Survey NDHS 2008 report that women with post secondary education and those with higher socioeconomic status use modern contraceptives more than their socially and economically disadvantaged counterparts. ${ }^{7}$ Similar findings were reported in separate studies carried out by Sambo et al and the International union for the scientific study of population (IUSSP)in Zaria. ${ }^{8,9}$

Unlike most of the studies initially conducted on this topic such as that of Babatunde et $\mathrm{al}^{10}$ Aisien et $\mathrm{al}^{11}$ and Ajayi et al, ${ }^{12}$ who recruited study subjects on only COCP, intradermal implant and injectable contraceptives respectively; the subjects for this study were recruited from individuals using all the readily available hormonal contraceptives namely COCP, POP, noristerat ${ }^{\circledR}$, Depo provera ${ }^{\circledR}$ implant and hormone containing IUD (Figure 4.2). This allowed for individual and comparative analyses of the effects of all the different forms on haemostatic parameters as shown in table 3. Similar studies with different forms were conducted by Joseph et $\mathrm{al}^{5}$ (COCP and Injectables), Prasad et $\mathrm{al}^{13}$ (different pharmacological formulations of oral contraceptives pills). Like our findings, each of the studies mentioned above showed appreciable differences between the various types in most of the haemostatic parameters analyzed.

In this study there was significant elevation in the fibrinogen and D-dimer $(\mathrm{p}<0.05)$ in users of hormonal contraceptive compared to those using non hormonal method. As shown on table 3. These findings were similar to that of Ahmed et $\mathrm{al}^{14}$ who carried out a study among Iraqi women on COCP and reported a significantly increased fibrinogen $(\mathrm{p}<0.05)$ and D-dimer $(p<0.001)$ when compared to non users. These reports were also in agreement with the findings of Babatunde and Olatunji ${ }^{10}$ in Ilorin-Nigeria who reported a significantly increased fibrinogen among hormonal contraceptive users. In contrast to the findings above; Paul Chan et al ${ }^{15}$ working in Chinese women reported no significant difference between fibrinogen level of users of hormonal contraceptives and non users.

The increase fibrinogen level potrays a procoagulant effect while the elevated plasma D-dimer level is an indication of increased fibrinolytic activity which protects against excess fibrin deposition within the vascular channels with its obstructive consequences. Thus, the hypercoagulable state is physiologically counteracted by the increased fibrinolysis and normal circulation is maintained as separately documented by Winker and Meijers et al. ${ }^{16,17}$ The increase fibrinolysis may also explain why the mean plasma fibrinogen of the hormonal contraceptive users though on the high side, was still within normal limits in this study. This is comparable to similar studies by Ajayi 
et al in Ekpoma ${ }^{12}$ and Famodu in Benin ${ }^{18}$ who individually reported an increase in plasma fibrinogen level among injectable contraceptive and COCP users respectively.

However, in both the Ajayi and Famodu studies, Euglobulin clot lysis time (ELT) was used for assessing fibrinolytic activity and was found to be prolonged indicating hypofibrinolysis. This was not in agreement with the increase fibrinolytic activity found in this study as evidenced by markedly elevated D-dimer levels. The variation could be due to the test method employed, more so these earlier studies used only a single form of contraceptive while our study used various forms. Though D-dimer assay is considered as a more sensitive test it is not done routinely in most haematology laboratories in Nigeria hence the ELT is still relevant in the assay for fibrinolysis.

In this study, each type of hormonal contraceptive has been shown to exhibit a procoagulant effect which manifested as an increased fibrinogen level in a significant percentage of users. However, while a sizable of those on progestogen only contraceptives has a corresponding elevated Ddimer level which suggests increase fibrinolytic activity; none of the client on COCP was found to have increase Ddimer level hence the procoagulant effect of increase plasma fibrinogen persists unchecked. Therefore, it could be inferred that the estrogen component of the COCP is responsible for this effect. This finding corroborates earlier reports by Kuhl et a $\mathrm{a}^{19}$ and Kenneth et $\mathrm{al}^{20}$ and indeed most researchers on this subject that the oestrogen component of the $\mathrm{HC}$ confers a higher incidence of haemostatic alteration and consequent thrombotic risk to the user.

It has been postulated that the thrombogenic risk associated with progesterone only contraceptives depend on the type, mechanism of delivery and length of therapy. ${ }^{21}$ This may explain why the pattern of haemostatic changes recorded was different for each form used in this study (Table 4.8).

\section{Conclusion}

The significant increase in the procoagulant protein, fibrinogen which is precursor of fibrin production and corresponding increase in fibrinolytic activity as demonstrated by elevated Ddimer level reflect a balance between fibrin formation and degradation hence minimizing the VTErisk.

However, this balance, though clearly seen among users of other forms of contraceptives was not observed among COCP users. This is attributable to the estrogen component of the COCP and may explain why it is associated with a higher thrombotic tendency.

\section{Acknowledgements}

All Staffs of Reproductive Health Clinic and Department of Haematology \& Blood transfusion Ahmadu Bello University Teaching Hospital, Zaria, Nigeria

\section{Funding}

The research was fully funded by the corresponding author

\section{Competing Interests}

The Authors declare no conflict of interest

\section{References}

1. McNaughton MC. Hormonal contraceptive: development and mode of action. In Loudon N (Ed). Handbook of Family Planning. Churchill Livingstone, New York.1986; 40-49.

2. Cardiovascular Disease and Steroid Hormone Contraception: Report of a WHO Scientific group. WHO Tech Rep Ser 1998; 877: 1-89.

3. Factsheet for women taking hormonal contraceptive or who will like information about them. BUPA's health information team publication, May 2010.

4. George PC. Hormonal contraception. In Betram GK (ed). Basic and clinical pharmacology. McGraw-Hills Companies New York. 9th ed 2006; 673- 678.

5. Joseph JT, Abdulazeez AA, Obisesan OA. Effect of hormonal contraceptives on some haemostatic parameters in women attending family planning clinics in Jos, Nigeria. Nigeria journal of health and Biomedical Science. 2008; 7 (1): $15-18$.

6. Vandenbroucke JP, Koster T, Briet E,Reitsma PH, Bertina RM, Rosendel FR. Increased risk of venous thrombosis in oral-contraceptive users who are carriers of factor V Leiden mutation. Lancet. 1994; 344: 1453- 1457.

7. Family planning: National Population Commission (NPC) and ICF Macro. 2009. Nigeria Demographic and Health Survey 2008: Key Findings. Calverton, Maryland, USA: NPC and ICF Macro. 5-6

8. Aliyu AA, Shehu AU, Sambo MN, Sabitu K. Contraceptive knowledge, attitudes and practice among married women in Samaru community, Zaria, Nigeria. East Afr J Public Health. 2010 Dec; 7(4): 342-344.

9. Knowledge and use of modern contraceptives among Muslim women in Zaria, Nigeria. Available at iussp2005. princeton.edu/papers/50788. [Accessed 27th January 2013]

10. Babatunde AS, Olatunji PO. Short term effect of oral contraceptive pills on some haemostatic parameters in healthy Nigerian women. The Nigerian Postgraduate Medical Journal.2004; 11 (4): 246 -250.

11. Aisien AO, Enosolease ME, Shobowale MO. Evaluation of haemostatic function in Nigerian Norplant ${ }^{\circledR}$ acceptors after 12 months of use. J Obstet Gynaecol. 2005; 25 (4): 377 381. 
12. Ajayi O, Ajayi O. Obarhua E. Haemostatic Evidence of Thrombotic Signaling in Nigerian Women on Injectable Contraceptives. Haematologica 2007; 92[suppl.2]:434.

13. Prasad RN, Koh S. Ratnam SS. Effects of three types of combined O.C. pills on blood coagulation, fibrinolysis and platelet function. Contraception. 1989; 39(4): 369-383.

14. Ahmed JA, Muna AK. Effect of combined oral contraceptive pills on some haemostatic parameters. Ann. Coll. Med. Mosul 2007; 33 (1\&2): 66-69.

15. Chan P, Paul CJ, Pan WH. Influence of Contraceptive pill use, Premenopausal and Postmenopausal State on Haemostatic Parameters in Ethnic Chinese Women: Journal of Thrombosis and Thrombosis and Thrombolysis. 1996; 3: 9-12.

16. Winkler UH. Blood coagulation and Oral Contraceptives: a Critical Review. Contraception. 1998; 57: 203- 209.

17. Meijers JCM, Middeldorp S, Tekelenburg W, et al. Increased Fibrinolytic activity during use of Oral Contraceptives is counteracted by an enhanced Factor XI-independent down regulation of Fibrinolysis: a randomized cross-over study of two low-dose Oral Contraceptives. Thromb Haemost 2000; 84: 9-14.

18. Famodu AA. Serial changes in plasma fibrinogen concentration and fibrinolytic activity in African women on oral contraceptive pills. Afr J Reprod Health. 1997; 1: 90-95.

19. Kuhl H, März W, Jung-Hoffmann C, Heidt F, Gross W. Time-dependent alterations in Lipid Metabolism During Treatment with Low-dose Oral Contraceptives. Am J Obstet Gynecol 1990; 163: 363- 369.

20. Kenneth AB, Gregory YH. Overview of the causes of VTE- oral and transdermal contraceptives available at http// www.update.com/content/overview of venous thrombosis. [Accessed 30th January 2013].

21. Cameron CT, Richard JC, Alan DM et al Hormonal Contraception and Thrombotic Risk: A Multidisciplinary Approach. Pediatrics. 2011; 127(2): 347-357.

*Corresponding author:

Dr. Sani Bako Abubakar, Postal Address: Department of Haematology UsmanuDanfodiyo University Teaching Hospital Sokoto, Nigeria.

Phone: +91 8035075121

Email: sbabubakar@yahoo.com

Financial or other Competing Interests: None. 